\title{
Epistemología y racionalismo crítico (Los griegos y Karl Popper)*
}

- Luis Armando González

"Llamo liberal, no al simpatizante de un partido político, sino simplemente al hombre que concede valor a la libertad individual y que es sensible a los peligros inherentes a todas las formas de poder y de la autoridad"

K. POPPER

A los estudiantes de la primera promoción de la maestría en Ciencia Política

\section{Introducción}

En la actualidad, tiene amplia aceptación la idea de que la "epistemología", como rama de la filosofía, se ocupa de las condiciones, límites y posibilidades del conocimiento científico. Esta fue la célebre definición de Kant, cuyo aporte es lundamental para la constitución de la epistemología como una disciplina intelectual moderna. La palabra ciertamente no es de origen moderno, pero su

$\therefore$ Este artículo recoge una parte de las notas del curso "Epistemologia de las Ciencias Sociales", ofrecido en el marco de la Maestria en Ciencia Política de la UCA (Semestre 0I, 200I). Para su publicación en Realidad se han añadido citas y referencias bibliográficas al texto original, y se ha modificado levemente el estilo y la reclacción.

Epistemologiv y racionalismo crî́tico (Los griegos y Kar Popper) 
campo de acción cognoscitivo sí lo es. En efecto, desde Kant, la epistemología no se ocupa de cualquier conocimiento, sino de uno en particular: el conocimiento científico que, para el filósofo alemán, encontraba su mejor formulación en la física de Galileo y Newton.

Para llegar a las tesis kantianas hubo de pasar bastante tiempo: el que va de Platón y Aristóteles al neoplatonismo (siglo II d. C.), y el que va de Descartes hasta el propio Kant. De este último en adelante, la epistemología ha avanzado en sus formulaciones, aunque sin dejar un saber polémico y no definitivamente concluyente en sus tesis fundamentales. La discusión ha sido y es particularmente intensa en las ciencias sociales, donde los intereses científicos se han mezclado con intereses ideológicos del más diverso signo, lo cual ha dado pie a las más agrias disputas y a generar no poca confusión.

Adicionalmente, la discusión epistemológica arrancó de las ciencias naturales como modelo de conocimiento científico. Al abordar la "epistemología de las ciencias sociales" fue ineludible que ese abordaje estuviera cargado con los referentes científico-naturales. Aquí se libró una dura batalla entre quienes se guiaron por este esquema y quienes pretendieron emancipar a las ciencias sociales de la tutela de las ciencias naturales. El famoso debate "explicación-comprensión" fue la expresión más llamativa de estos dos modos de entender y abordar los problemas epistemológicos de las ciencias sociales'.

El objetivo de estas notas recoger, en el marco del horizonte abierto por Jenófanes y Parménides, algunos de los problemas epistemológicos más importantes, sobre todo aquellos que, de la mano de Karl Popper - y en el marco de una tradición que se puede denominar "racionalismo crítico"-, cobran relevancia durante el siglo XX y que son piezas importantes para la elaboración de una epistemología de las ciencias sociales. Aun es digna de consideración la constatación de José María Mardones y Nicolás Ursúa —efectuada a principios de los años 80 - en el sentido de que "en el ámbito de las ciencias humanas y sociales todavía no se ha llegado a obtener un consenso acerca de la fundamentación científica". Es decir, que nos "encontramos sin una teoría de la ciencia o epistemología"? Por eso mismo, es urgente ir perfilando las líneas maestras de una teoría de la ciencia que justifique la cientificidad de los estudios sociales.

\section{El problema del conocimiento para los griegos}

Comencemos, antes que nada, por el significado de la palabra "epistemología". Pues bien, la misma está formada por dos términos griegos: episteme y logos. La palabra logos fue usada por los presocráticos (Heráclito, Parménides, Anaximandro, por ejemplo) y su significado se mantuvo prácticamente durante toda la época clásica en Grecia. Logos es conocimiento conseguido a partir se razones; conocimiento que da razones, es decir, quc convence con razones (argumentos). 
Mientras tanto, se tiene noticias de que uno de los primeros filósofos que usó la palabra episteme de un modo sistemático fue Aristóteles de Estagira, en el siglo V antes de Cristo. Para Aristóteles, episteme es conocimiento verdadero, conocimiento cierto e irrefutable. Es decir, conocimiento demostrable, científico, como el de las matemáticas. Aristóteles "cree que conoce, cree que él mismo posee episteme, conocimiento científico demostrable... Lo que para Platón era una hipótesis científica se convierte en Aristóteles en episteme, conocimiento demostrable, y desde entonces ha continuado siendo así para la mayoría de epistemólogos de occidente".".

Los griegos no usaron la palabra "epistemología", pero según sus raíces griegas vendría a querer significar algo así como "conocimiento que da razones del conocimiento verdadero, del conocimiento científico". Brevemente, con ella se quiere decir conocimiento (logos) acerca del conocimiento (episteme). Sólo que mientras la primera parte de la expresión indica un "proceso", la segunda se refiere a algo ya logrado. Más o menos, ese es el significado de la palabra en la actualidad. Pero, hay que insistir en que la palabra es de uso reciente e incluso hasta hace poco - en pleno siglo XIX - se usaron dos palabras: gnoseología (en la tradición rusa) y teoría del conocimiento (en la tradición alemana e inglesa)4.

Pues bien, aunque los griegos no usaron la palabra "epistemología", sí se preocuparon por los problemas fundamentales del conocimiento humano. Fueron, en este sentido, los grandes precursores y gestores de la epistemología. El abordaje que hacen los griegos del problema del conocimiento tiene los siguientes componentes.

a) El problema de la verdad. Ya los presocráticos se hacen la pregunta de cuál es la realidad fundamental de las cosas (la naturaleza) y de cómo esa realidad se hace presente en la inteligencia humana. La verdad tiene, desde aquí, una doble cara: la que ve a las cosas y la que ve a la inteligencia. "La verdad como concepto - dice Xavier Zubiri- entra en la historia de la filosofía por primera vez allá en el siglo VI, con Parménides de Elea... La verdad tiene, pues, para Parménides un cierto carácter de rotundidad. Una rotundidad que para él se expresa precisamente en la disyunción: aquello a que se aplica el término de verdad, o es o no es"s.

b) Dicho esto, surge a la par de ello, el problema de los límites de la inteligencia humana para aprehender la verdad de las cosas. Es Parménides de Elea (515-450) quien se hace esta pregunta de una forma sistemática y ofrece una respuesta que incidió en la reflexión posterior. La respuesta de Parménides es la de la "doble vía" para acceder a la verdad.

La vía de la Diosa Diké (vía del conocimiento verdadero) que sí puede acceder al conocimiento pleno de la realidad. Sólo a ella le es dable acceder a la verdad demostrable revelada por la Diosa.

Epistemología y racionalismo critico (Los griegos y Karl Popper) 
La vía humana (vía del conocimiento conjetural) que, atrapada en las apariencias ofrecidas por los sentidos, sólo puede ofrecer conjeturas, aproximaciones, sin poder atinarle nunca a lo que es en verdad la realidad. La vía humana ofrece ( $\mathrm{y}$ descansa en) opiniones de los mortales ${ }^{6}$.

c) En Parménides se dibuja con claridad el tercer problema epistemológico: el de la verdadera realidad y las apariencias. Según esto, una cosa es lo que se nos da inmediatamente a través de los sentidos y, otra muy distinta, lo que está detrás de lo aparente (de lo que aparece): para acceder a la verdad de la realidad hay que sortear precisamente lo aparente, lo cual para Parménides es humanamente imposible, siendo que, por culpa de la luz, el hombre está condenado a ser confundido por sus sentidos y, por tanto, a formular puras conjeturas. Antes de Parménides, otro presocrático, Jenófanes (570-475), había sido más radical en cuanto a las posibilidades humanas de acceder a la verdad de la realidad, puesto que para él aunque ello sucediera por accidente el hombre ni cuenta se daría, "pues todo no es sino una maraña de sospechas".

d) El cuarto problema epistemológico de los griegos tiene que ver con el papel de los sentidos como obstáculos para el conocimiento verdadero. Desde Parménides hasta Platón y Aristóteles se elabora una severa crítica a quienes piensan que los sentidos son fuente de conocimiento. En esta tradición antiempirista, los sentidos son una trampa, engañan y atrapan al ser humano en las apariencias. Para el primero de los autores referidos arriba, el problema estriba en que "cuanto se halla en un momento en la mezcla de los engañosos órganos sensoriales, eso les parece genuino conocimiento a los hombres, pues tienen por lo mismo la humana mente y la variable naturaleza de sus órganos sensoriales"?

c) Quinto problema epistemológico: el del pesimismo y optimismo acerca de cucinto o qué se puede conocer de la realidad. En Parménides la situación es clara: es un pesimista epistemológico. Al hombre le está vedado acceder a la verdad plena de la realidad; en consecuencia, sólo le queda elaborar conjeturas, aproximaciones a lo que presumiblemente es la realidad. Aristóteles, por el contrario, es un optimista epistemológico: cree que el hombre, el sabio, puede llegar a un conocimiento verdadero, a la episteme. Tenemos episteme cuando tenemos definiciones. "El objeto de la episteme, de la ciencia, no es sólo un 'por qué' universal (...), sino un 'por qué' universal por necesario... La Lógica es el camino (...) que conduce a ese logos de lo que la cosa 'es' necesariamente".x.

Sócrates - - Sócrates "histórico"- quizás está más cerca de Parménides que de Aristóteles. Para él, lo que no sabemos es inlinitamente más amplio que lo que sabemos. Y justamente es de sabios caer en la cuenta de ello. Pero eso es un acicalc para avanzar en búsqueda, del conocimiento de lo que son las cosas. El lema socrático, "sólo sé que no sé nada", expresaba esa voluntad de conocimicnto que el filósofo intentaba transmitir a quienes se atravesaban en su camino. El lema "conócete a ti mismo" obligaba, ante todo, a cxplorar en el interior de la

\section{6}

Realidad 81, 2001 
propia subjetividad, de la propia conciencia. “'Conócete a ti mismo' significa: adquiere conciencia de tu fin y de tus faltas reales; la primera de éstas, la que impide toda enmienda espiritual, es la creencia de no tener faltas, esto es, la falta de conocimiento de sí mismo y de la verdad que se esconde bajo la ilusión y pretensión de sabiduría. Saber que no se sabe, es decir, adquirir conciencia de los problemas y de las lagunas que escapan a la pretendida sabiduría: he ahí el primer resultado del examen y conocimiento de sí mismo, primera sabiduría verdadera"'.

Por su parte, Platón (427-347) se mueve en ambiguamente en este punto (del optimismo y del pesimismo epistemológicos). Hay que considerar las ideas filosóficas de Platón: el mundo está formado por dos realidades: (a) las apariencias y (b) las esencias verdaderas, es decir, las ideas (por ejemplo, bien, humanidad y justicia). El mundo de las apariencias en una copia "deformada" del mundo de las esencias. Por un proceso de corrupción (evolutivo) difícil de explicar, el mundo de las ideas tuvo una "caída" en lo corporal. El conocimiento verdadero es el conocimiento de ese mundo de las ideas posibilitado por los "recuerdos" de cuando el hombre perteneció a ese mundo de las esencias.

Pues bien, en textos como el Menón, Platón dice que a todos los hombres les ha sido dada la facultad de "recordar" su vida antes de ser mortales (en el mundo de las ideas verdaderas). Por ese recuerdo -anaminesis-todos los podemos entrar en posesión de la verdad. En este sentido, hay en Platón un optimismo epistemológico. Como señala Popper, "Sócrates demuestra lo que antecede cn un hermoso pasaje del Menón, cuando ayuda a un joven esclavo sin educación a 'recordar' la prueba de un caso especial del teorema de Pitágoras. Encontramos aquí, realmente, una epistemología oplimista y la raíz del cartesianismo. Pareciera que, en el Menón, Platón era consciente del carácter sumamente optimista de su teoría, pues la describe como una doctrina que considera al hombre ansioso por aprender, investigar y descubrir"

Pero, en otros textos Platón plantea tales dificultades al proceso de conocimiento que más bien se acerca a una postura pesimista o a un optimismo que sólo es válido para unos pocos (los sabios). De nuevo, citemos a Popper: "Platón - dice- debe haber sufrido un desengaño, pues en la República (y también el Fedro) hallamos los comienzos de una epistemología pesimisla. En la lamosa alcgoría de los prisioneros de la caverna (...) indica que el mundo de nuestra expericncia es sólo una sombra, un reflejo, del mundo real. Y muestra que, aun cuando uno de los prisioneros escapara de la caverna y enfrentara el mundo real tendría dificultades casi insuperables para verlo y comprenderlo... Las dificultades que se alzan en cl camino de la comprensión del mundo real son casi sobrehumanas, y sólo muy pocos — si es que hay alguno- pucden llegar al estado divino del verdadero conocimiento, de la episteme" "I. 
Para cerrar esta discusión sobre el problema del conocimiento para los griegos, vamos a ilustrar los temas abordados con los siguientes textos de Jenófanes (570-475 a C) y Parménides (515-450 a C) $)^{12}$.

Sócrates -el Socrátes "histórico"-quizás está más cerca de Parménides que de Aristóteles. Para él, lo que no sabemos es infinitamente más amplio que lo que sabemos. $Y$ justamente es de sabios caer en la cuenta de ello.

\section{JENÓFANES}

\section{Sobre Dios}

"Uno solo es Dios entre los dioses y' uno entre los hombres es el máximo.

Ni en entendimiento ni en cuerpo se asemeja a los mortales.

Siempre permanece en un lugar sin moverse nunca.

Sin esfuerzo sobre el Todo reina con el simple pensamiento e intención.

Todo él ve, todo él conoce y' todo él oje"

\section{Sobre el conocimiento cierto}

"Mas por lo que respecta a la verdad cierta, nadie la ha conocido.

Ni la conocerá; ni acerca de los Dioses

ni siquiera de todas las cosas de las que hablo.

$Y$ aunque por casualidad expresase

la verdad perfecta, ni él mismo lo sabria;

pues todo no es sino una maraña de sospechas".

\section{Optimismo epistermológico "moderado"}

"Los dioses no nos revelaron desde el principio

todas las cosas; sino que con el transcurso del tiempo

podenos aprender investigando y conocer las cosas.

Esto, como bien podremos conjeturar, se asemeja a la verdad".

Tras el "giro lingüístico" en filosofía quedó claro que las visiones simplistas del conocimiento científico tenían que ser abandonadas. En el marco del giro lingüistico cobró fuerza la idea de que "los problemas filosóficos pueden ser resueltos (o disueltos) reformando el lenguaje o comprendiendo mejor el que usamos en el presente. 


\section{Parménides}

\section{Las dos vías de la Diosa}

“ ¿Escucha y propaga mi mensaje cuando lo hayas entendido!

Repara en las dos únicas vías de investigación concebibles:

Una es la vía de que es y de que no-ser no puede ser.

Se trata de la senda de la Persuasión, acompañante de la Verdad; ahora la otra vía.

Esta senda es la de que no es y de que ha de no ser.

Esta senda, créeme, es una senda en la que no se puede pensar.

Pues lo que no es no se puede saber, no se puede hacer ni se puede decir".

"Aqui termino mi discurso fidedigno.

$Y$ mis pensamientos claros sobre la verdad. Aprende ahora conjeturas humanas".

\section{Contra el empirismo}

"Lo que está en cualquier momento en los engañosos órganos de los sentidos,

Eso les parece a los hombres conocimiento genuino, pues tienen por lo mismo

La mente intelectual del hombre y la cambiante naturaleza de sus órganos de los sentidos.

Llaman "pensamiento" a lo que prevalece de este embrollo en todos y cada uno de los hombres".

"Nunca se concederá que las cosas que no son existan.

Apartan tu pensamiento de esta vía de indagación; no permitas que la experiencia

Y la rutina se te impongan. Y no dejes errar tus ciegos

Ojos o tus sordos oidos, ni siquiera tu lengua, por esa vía".

\section{Pesimismo epistemológico}

"Pues nunca podrás conocer lo que no existe verdaderamente, Ni podrás siquiera describirlo..."

\section{El planteamiento de Karl Popper}

Tras el "giro lingüístico" en filosofía quedó claro que las visiones simplistas del conocimiento científico tenían que ser abandonadas. En el marco del giro lingüístico cobró fuerza la idea de que "los problemas filosóficos pueden ser

Episłemologia y racionalismo crítico (Los griegos y Karl Popper) 
resueltos (o disueltos) reformando el lenguaje o comprendiendo mejor el que usamos en el presente. Esta perspectiva es considerada por muchos de sus defensores el descubrimiento filosófico más importante del nuestro tiempo y, desde luego, de cualquier época"|?. Era claro que, en el conocimiento científico, no se trataba de un "contacto" directo de los sentidos humanos con la realidad. Ese contacto estaba mediatizado por la carga lingüística que todo ser humano lleva consigo.

El hombre de ciencia no es la excepción; más bien es la confirmación de la regla. En su caso, se trata de un bagaje teórico que le sirve para orientar sus experiencias. Siendo así las cosas, lo que se impuso, a contracorriente del empirismo y el positivismo, fue un retorno a Kant. Claro está, no se trató de una repetición de las tesis kantianas, sino de su puesta a punto. Lo que se recupera es la idea kantiana de que el científico, cuando conoce, no lo hace palpando sensiblemente las cosas para que éstas lo impacten, sino que hay un "antes" previo a su experiencia. Es decir, hay un punto de partida inicial previo a la experiencia. Algo así como un "a priori".

¿Cuál es ese punto de partida? ¿Cómo entender ese “a priori”? Es aquí donde aparece en escena Karl Popper (1902-1994). Vamos a abordar su aporte en tres niveles: (a) su teoría del conocimiento (epistemología); (b) su epistemología genética; y (c) su teoría de los mundos 1, 2 y 3.

\subsection{Teoría del conocimiento}

\subsubsection{Planteamiento epistemológico general}

Iniciemos con la formulación de tres tesis que son claves en el planteamiento epistemológico de Karl Popper.

Tesis 1: El proceso de conocimiento cientifico tiene como punto de arranque el surginiento y la formulación de un problema. Problema: algo que contradice lo que ya se sabe o que contradice algo que es altamente predecible.

Tesis 2: De lo que se trata es de avanzar en el conocimiento de la realidad'4. $y$ sólo se puede agregar nuevo conocimiento, sobre lo ya conocido, cuando el problema que se quiere abordar, es decir, al que se quiere encontrar solución, no la tiene o la que tiene es insatisfactoria. Es esa novedad, por mínima que sea, la que tiene que ser expresada en el problema que ocupa al científico.

Tesis 3: Los dos ejes del conocimiento científico son los problemas y sus intentos de solución.

Pues bien, ¿de dónde surge el problema?

Ante todo, están aquellos que opinan que el problema surge de la experiencia de quien investiga. Según éstos, aquellos que tienen más contacto con la realidad 
son los que mejores problemas plantean. O dicho de otra forma: que para formular verdaderos problemas hay que empaparse de realidad. Sintiendo, tocando, observando, oliendo... Luego se traducen esas experiencias en expresiones verbales, con las que se intenta explicarlas. Pero no basta con eso: se tiene que regresar a la experiencia, para verificar su valide $z^{15}$.

\section{Esquema l: experiencia $\longrightarrow$ problemas $\longrightarrow$ explicación teórica $\longrightarrow$ experiencia}

En segundo lugar, quienes opinan que surge de la imaginación pura. Es decir, de la creatividad del individuo que investiga, creatividad que en cuanto tal no tiene un fundamento racional, sino que obedece más bien a una intuición lúcida que luego es racionalizada. En este óptica, no todos los humanos están capacitados para descollar originalmente en la investigación científica, sino sólo los dotados con un toque de genialidad. Habrá muchos repetidores incansables, los hombres hormiga que trabajan incansablemente. Pero al genio le brota la idea original, no se sabe cómo ni dónde, que hace avanzar al conocimiento ${ }^{16}$.

Esquema 2: intuición $\longrightarrow$ problemas $\longrightarrow$ planteamiento racional (verbal) $\longrightarrow$ experiencia

En tercer lugar, están los que sostienen que un problema científico nace de las teorías establecidas (o del saber científico establecido), en las cuales se detecta (por creatividad, intuición o revisión permanente) un déficit que tienen que ser solventado. Ese déficit, que puede ser leve, parcial o total, una vez que se detecta se convierte en un problema para el investigador, el cual se ve forzado a hacer uso de sus mejores recursos teóricos (conceptuales) para formularlo con claridad y simplicidad. Pero no sólo eso. Según esta tercera perspectiva, una vez lormulado el problema se ensaya una respuesta tentativa (conjetura o hipótesis) al mismo, para lo cual el investigador (teórico) se vale no sólo los conocimienlos disponibles, sino de sus propias formulaciones-innovaciones conceptuales.

Esa respuesta es sometida después a la prueba de la experiencia, con el propósito de mostrar su falsedad. Si resiste - y mientras resista las falsaciones a que se someta - se la tendrá por científicamente àceptada.

Esquema 3: teorias establecidas (conjeturas aceptadas) $\rightarrow$ problema $\longrightarrow$ respuesta tentativa (hipótesis o conjetura a falsar) $\rightarrow$ falsación por la experiencia o por el análisis teórico

Esta es la propuesta de Popper acerca de cómo se procede en el mundo de la ciencia. El lo llama procedimiento de las "conjeturas y refutaciones" o método lalsacionista. Lo fundamental en el mismo es que la actividad científica se caracteriza por el ejercicio sistemático de la refutación o falsación de las teorías estableci-

Epistemología y racionalismo crítico (Los griegos y Kor Popper) 
clas o de nuevas hipótesis. "Aprendemos siempre muchísimo por medio de una lalsación" --dice Popper. Y continúa: "no sólo aprendemos que una teoría es falsa, sino que también aprendemos por qué es falsa. Y sobre todo, obtenemos un nuevo problema, más rigurosamente formulado; y un nuevo problema es, como ya sabemos, el verdadero punto de partida de un nuevo desarrollo científico"17.

En estc mismo escrito, Popper propone el siguiente esquema de cuatro etapas para cntender la lógica del conocimiento científico:

a) cl antiguo problema;

b) lormaciones teóricas a modo de prueba;

c) intentos de eliminación por medio de la discusión crítica, incluido el examen experimental;

d) los nuevos problemas, que surgen de la discusión crítica de las teorías.

A continuación dice lo siguiente: "mi esquema de cuatro etapas permite hacer una serie completa de observaciones teórico-cientílicas. Sobre el problema. Los problemas precientíficos y los problemas cientílicos primarios son de naturaleza práctica, pero pronto son sustituidos, en virtud del ciclo de cuatro etapas, por problemas teóricos, al menos en parte. Es decir, la mayoría de los nuevos problemas surgen de la crítica de las teorias: son intrateóricos... Dichos problemas teóricos son, fundamentalmente, preguntas por las explicaciones, por las tcorías explicatorias: las respuestas a modo de prueba, que suministran las teorías, son en efecto intentos de explicación"'k.

¿Qué son las teorias? En rigor, son un conjunto de "conjeturas" que se aceptan en tanto en cuanto no se ha encontrado la refutación parcial o total de ellas. "El concepto moderno de ciencia - - el de que las teorías científicas son esencialmente hipotéticas o coyunturales y de que nunca podemos tener la seguridad de que incluso la teoría mejor establecida no sea destronada y sustituida por una aproximación mejor_ es, a mi entender, resultado de la revolución einsteiniana"|".

¿Acerca de qué son esas hipótesis (o conjeturas)? Sobre cómo es la realidad, cómo funciona y cómo nos afecta. Es decir, se trata de aproximaciones a la verdad de la realidad: conjeturas (aproximaciones) $\rightarrow$ Verdad de la Realidad.

En este esquema aparecen las tres "ideas regulativas" que, según Popper, deben regir la actividad científica: la idea de verdad; la idea del contenido lógico y empírico de una teoría; y la idea del contenido de verdad de una teoría y de la aproximación a la verdad.

"Puede observarse que la idea de verdad domina la discusión crítica en el hecho que discutimos críticamente las teorías con la esperanza de eliminar las falsas teorías. Esto muestra que estamos guiados por la idea de la búsqueda de teorías verdaderas... La segunda idea regulativa, la idea del contenido de una 
teoría, nos conduce a buscar teorías con gran contenido informativo... El contenido lógico de una teoría es su masa deductiva, es decir, la cantidad o clase de todas las proposiciones que se pueden deducir lógicamente a partir de la teoría en cuestión... Quizás sea todavía más interesante la idea del contenido empírico de una teoría. Para comprender esta idea, partimos de que una ley empírica o una teoría empírica prohibe ciertos procesos observables... Por lo tanto, puede designarse el contenido empírico de una teoría como la cantidad o la clase de proposiciones empíricas prohibidas por la teoría; es decir, como la cantidad o la clase de las proposiciones empíricas que entran en contradicción con la teoría... La idea de aproximación a la verdad presupone... una concepción realista del mundo. No presupone que la realidad es tal y como la describen nuestras teorías científicas; pero presupone que existe una realidad y que podemos aproximarnos más y más a una descripción adecuada de la realidad con nuestras teorías, que son ideas creadas por nosotros mismos $y$, por eso, siempre idealizaciones, si aplicamos el método de ensayo y error en cuatro etapas"20".

Ahora bien, como de lo que se trata es de acercarse más a la verdad de la realidad, se tiene que buscar en qué fallan esas aproximaciones (conjeturas), así como los mecanismos para su refutación en orden a buscar otras mejores. Es decir, las teorias vigentes deben ser permanentemente revisadas, problematizadas y sometidas a nuevas "pruebas experimentales".

¿De qué tipo de pruebas experimentales se trata? De aquellas que sean capaces de falsar la teoría (o la conjetura) sometida a examen. No de una prueba que lc verifique, sino que demuestre su falsedad. Si resiste, se la seguirá aceptando como una explicación legítima hasta que no sea refutada. Si no resiste, se formulará otra conjetura, que a su vez deberá ser falsada. Esto lleva a un segundo tip̄o de procedimiento de falsación: cuando se trata de hipótesis o conjeturas altcrnativas a las teorías vigentes. Aquí el proceso es el mismo, aunque sólo en contadas ocasiones la nueva conjetura resiste la prueba de la falsación. Cuando cso sucede, sc suele conservar la teoría vigente.

En este marco se genera una lucha de teorias y de conjeturas; en esa lucha, los abanderados de las nuevas teorías y las nuevas conjeturas aparecen como los innovadores, en tanto que los que defienden las teorías y conjcturas establecidas asumen una postura dogmática, que es necesaria para que los innovadores empleen a fondo sus energías intelectuales para defender los nuevos planteamientos. Se trata, pues, de una situación la cual el dogmatismo se enfrenta a la innovación, siendo ambos aspectos necesarios para el desarrollo científico ${ }^{21}$. En palabras de Popper:

"El conocimiento, especialmente el conocimiento científico, progresa a partir de soluciones injustificadas (e injustificables), de presunciones, de soluciones lentativas para nuestros problemas, de conjeturas. Estas conjeturas son controladas por la crítica; esto es, por intentos de refutaciones, entre las que 
se cuentan tests severamente críticos. Ellas pueden sobrevivir a esos tests, pero nunca pueden ser justificadas categóricamente: no se las puede establecer como indudablemente verdadera, ni siquiera como 'probables'... La misma refutación de una teoría —es decir, de una solución tentativa seria para nuestro problema - es siempre un paso adelante que nos acerca a la verdad. Y esta es la manera por la cual podemos aprender de nuestros errores"22.

Como quiera que sea, la conjetura a refutar (o falsar) debe tener como característica precisa la de ser falsable, es decir, refutable a partir de la experiencia. Sólo esas conjeturas añaden al conocimiento científico establecido. Aquí es pertinente señalar que lo falsable no es igual a lo altamente probable. En este punto Popper es tajante en su juicio sobre la probabilidad. Para él, lo altamente probable añade poco o nada al conocimiento científico. Mientras que sucede lo contrario con la discusión de lo altamente improbable. El siguiente texto es iluminador al respecto:

"No puede haber duda de que la probabilidad absoluta de una afirmación $a$ es simplemente el grado de su debilidad lógica o su carencia de contenido informativo, y de que la probabilidad relativa de una afirmación $a$, dada una afirmación $b$, es simplemente el grado de su relativa debilidad, o la relativa carencia de nuevo contenido informativo en la afirmación $a$, suponiendo que ya tengamos información de $b$.

"Por tanto, si en ciencia apuntamos hacia el objetivo de un alto contenido de información - si el desarrollo del conocimiento significa que sabemos más, que sabemos $a$ y $b$, y no sólo $a$, y que así se incrementa el contenido de nuestras teorías-, entonces tendremos que admitir que apuntamos hacia un bajo grado de probabilidad, en el sentido del cálculo de probabilidades"2?

En fin, es como si falsación y probabilidad fueran en sentido inverso. Lo que cs rico en posibilidades de refutación abre un campo amplio al conocimiento científico. Mientras que lo que es altamente probable empobrece el conocimiento científico si se centra excesivamente la atención en ello: "como un bajo grado de probabilidad equivale a un alto grado de falsabilidad potencial, de falsilicación, de aquí se colige que un alto grado de falsacabilidad, o de refutabilidad, o de comprobabilidad, es uno de los objetivos de la ciencia; de hecho, precisamente el mismo objetivo que un alto contenido informativo"24.

Volvamos al punto de partida: el problema.

Para Popper, el científico se caracteriza por su búsqueda de problemas, es decir, por la búsqueda de aquello que pueda ir a contracorriente del saber establecido. "El trabajo científico no comienza por la recolección de datos, sino por la sclección sensible de un problema prometedor, un problema que sea significalivo dentro de la actual situación problemática, que a su vez está completamente dominada por nuestras teorías"29. 
En esa búsqueda tratará de encontrar respuesta a lo que ya se sabe desde lo que no se sabe. "Se me ocurre que el objetivo de la ciencia - dice- estriba en encontrar explicaciones satisfactorias de cualquier cosa que parezca no tener explicación... Así, la explicación científica, siempre que sea un descubrimiento, será la explicación de lo conocido por medio de lo desconocido"26.

Es sobre esto desconocido (que el saber establecido no explica) que lanzará sus conjeturas, que luego serán sometidas a la prueba de la falsación por el mismo o por sus colegas. Sólo en muy contadas excepciones las nuevas conjeturas resisten la prueba de la falsación. Cuando esto sucede, se puede operar un cambio drástico en las explicaciones vigentes. Normalmente, las explicaciones vigentes resisten la revisión permanente a que se ven sometidas.

\subsubsection{Ciencias naturales y ciencias sociales}

Lo anterior permite arribar a una problemática que es central en Popper: la relación entre ciencias naturales y ciencias sociales. Ante todo, recojamos la tesis fundamental de Popper al respecto. "Tanto las ciencias naturales como las sociales - nos dice- parten siempre de problemas; de algo que despierta nuestra admiración, como decían los filósofos griegos. Las ciencias utilizan en principio para resolver esos problemas el mismo método que emplea el sano entendimiento humano: el método de ensayo y error. Expresado con más exactitud: es el método de proponer tentativamente soluciones de nuestro problema y después climinar las falsas soluciones como erróneas. Este método presupone que trabajamos con una pluralidad de soluciones a modo de prueba. Una solución es puesta a prueba y eliminada"27. Es decir, ambos tipos de ciencias parten de situaciones problemáticas enmarcadas en determinadas interpretaciones teóricas. Esto lleva a la reformulación del esquema 3 (visto arriba): problemas $\rightarrow$ teorías (conjeturas $)$ críticałproblemas

En otras palabras, para Popper el modo (método) de proceder falsacionista es propio tanto de las ciencias naturales como de las ciencias sociales. Sociología, antropología, ciencia política, historia, economía... Se ha pensado que son ciencias distintas porque se ha creído que las ciencias naturales proceden por observación e inductivamente, mientras que las ciencias sociales proceden mediante la interpretación. Así, las primeras serían objetivas mientras que las otras tendrían que luchar contra la subjetividad.

Lo anterior no es tan cierto para Popper, pues tanto las ciencias naturales como las sociales deben enfrentar el problema de la "objetividad científica". ¿Cómo? Mediante la discusión crílica de las teorías (interpretaciones) vigentes. "Lo que llamamos objetividad científica —señala Popper- es simplemente la no aceptación de teoría científica alguna como dogma. Y al mismo tiempo la afirmación de que todas las teorías sean tentativas y estén permanentemente abiertas a severa crítica, a una discusión crítica que tienda a la eliminación de

Epistemología y racionalismo crílico (Los griegos y Karl Popper) 
errores. En realidad no hay nada, pienso, que pueda explicar mejor la idea algo abstracta de racionalidad que el ejemplo de una discusión crítica bien conducida... Los científicos que participan en la discusión crítica tratan constantemente de refutar la teoría, o por lo menos su afirmación de que puede solucionar un problema" 2 .

Lo anterior supone, como ya se señaló, no tomar ninguna teoría científica como un dogma, sino como algo que seguramente tiene fallas que es necesario encontrar. Y así con todas las teorías, incluso la propia. ¿Cuál es la que se acepta? La que resiste mejor los intentos de falsación, no la que es verdadera, pues lo único que se puede suponer es que la teoría que resiste mejor la discusión crítica se "aproxima" más a la verdad. Pero nada más.

Sobre ese trasfondo común, las ciencias naturales y las sociales comparten otro aspecto fundamental: ambas requieren, para estudiar algunos problemas fundamentales, de la construcción de modelos que permitan explicar cierta clase o tipo de acontecimientos ${ }^{21}$.

Ahora bien, en las ciencias sociales la utilización de modelos lleva a construir situaciones o condiciones típicas. ¿Acerca de qué? Acerca de acciones humanas y situaciones sociales. Es esto justamente lo que diferencia a las ciencias sociales de las naturales. Su campo problemático de investigación. No su modo de proceder metodológico que en lo fundamental es el mismo. Es decir, "en las ciencias sociales existe un método puramente objetivo que puede bien denominarse el método objetivamente comprensivo, o lógica de la situación... Su método consiste en el análisis de la situación de los hombres que actúan lo suficiente como para explicar su conducta a partir de la situación misma, sin más ayudas psicológicas" "o!.

Un concepto clave es el de situación social. Los modelos de las ciencias sociales son descripciones o construcciones de situaciones sociales típicas. Así, la categoría "situación social" es la categoría lundamental en la metodología de las ciencias sociales. De este modo, en ciencias sociales es necesario realizar un "análisis situacional", para entender la lógica de una situación social concreta o la "lógica situacional". "La descripción de una situación social histórica concreta es lo que en ciencias sociales corresponde al enunciado de las condiciones iniciales cle las ciencias naturales. Y los 'modelos' de las ciencias sociales tcóricas son en esencia descripciones o construcciones de situaciones sociales típicas" ${ }^{\text {"31. }}$.

Scgún Popper, los acontecimientos sociales sólo pueden ser explicados y comprendidos a partir del análisis situacional. De la construcción de un modelo siluacional. Se trata de un modelo teórico-metodológico, que habrá de ser contrastado con la experiencia o deberá ser comparado con otros modelos. "Las contrastaciones de un modelo, habría que admitirlo, no son fácilmente obtenibles y en gencral no son demasiado nítidas. Pero esta dilicultad surge incluso en las 
ciencias físicas. Naturalmente, está en conexión con el hecho de que los modelos son siempre y necesariamente sobresimplificaciones redimentarias y esquemíticas. Su carácter rudimentario implica un grado comparativamente bajo de contrastabilidad"'?

Por otra parte, el sostén metodológico del análisis situacional es el "principio de racionalidad": los agentes sociales siempre actúan de una manera apropiada a la situación en que se encuentran. No se trata de una proposición empírica no psicológica, sino metodológica. Discutible y reemplazable por otro criterio, obviamente. Pero se trata de un criterio metodológicamente útil. "Se puede, por lanto, considerar la adopción del principio de racionalidad como subproducto de un postulado metodológico. No desempeña el papel de una teoría empírica explicativa, de una hipótesis contrastable. Pues en este campo, las teorías empíricas explicativas o hipótesis son más nuestros diversos modelos, nuestros diversos análisis situacionales. Estas podrían ser más o menos adecuadas empíricamente, lo que se podría discutir y criticar, y cuya adecuación podría a veces incluso ser contrastada, de donde, en caso de fracasar, nos habilitarían para aprender de nuestros errores"

¿Cómo se aplica ese modelo a los estudios históricos? Nos obliga, dice Popper, a examinar la historia como una historia de situaciones sociales problemáticas que sc sucedieron en el pasado. "Lo que he dicho hasta ahora es un breve esbozo de la metodología de las ciencias explicativas sociales, especialmente la tcoría económica y la antropología social. Pero se aplica en particular a las explicaciones históricas, que siempre operan con una reconstrucción racional de una situación. Tal vez el mejor campo para esta metodología sea la historia de la ciencia. Aquí la situación del agente - el científico creador- es la situación problemática que encuentra en su campo científico, aunque podría, por supuesto, volver a enmarcarla contemplándola de otra manera. Se podría generalizar y decir que toda vez que deseemos explicar o comprender la historia, tenemos que contemplarla como una historia de situaciones problemiáticas ${ }^{34 . "}$.

¿Y la sociología? El postulado anterior también vale para esta disciplina científica. "Quizás podamos adoptar provisionalmente como los problemas fundamentales de una sociología puramente teórica, en primer lugar el estudio de la lígica general de las situaciones, y en segundo lugar la teoría de las instituciones y de las tradiciones. Lo cual acogería problemas como los siguientes: 1. Las instituciones no actúan; sólo actúan los individuos en o para las instituciones. La lógica situacional general de esas acciones sería la teoría de las cuasiacciones de las instituciones. 2. Podemos formular una teoría de las consecuencias institucionales intencionadas y no intencionadas de la acción finalista. Esto llevaría a una teoría de la creación y desarrollo de las instituciones"

En resumen, las ciencias naturales y las ciencias sociales comparten el esquema metodológico general que sigue a continuación:

Episfemología y racionalismo crítico (Los griegos y Korl Popper) 


\section{Problemas $\rightarrow$ conjeturas $\$$ falsación (discusión crítica) $\rightarrow$ problemas}

En las ciencias naturales, el campo problemático son las explicaciones sobre fenómenos no humanos. En las ciencias sociales, las explicaciones sobre fenómenos humanos del pasado y del presente. Para acercarse a sus respectivos campos problemáticos ambas construyen modelos sobre situaciones típicas que permitan explicar los casos que se acercan a ellas. En otras palabras, las ciencias sociales se relieren a situaciones relativas a acciones humanas y situaciones sociales. Esquemáticamente:

CCNN: Problemas $\rightarrow$ conjeturas $\rightarrow$ falsación (construcción de modelos)

$\rightarrow$ problemas

CCSS: Problemas $\rightarrow$ conjeturas $\rightarrow$ falsación (análisis situacional) $\rightarrow$ problemas

\subsection{Epistemología genética (evolutiva) $)^{36}$}

El análisis anterior tiene que ver con el conocimiento científico ya consolidado, es decir, tal como es en la actualidad. Pero, desde una perspectiva histórica, ¿qué hubo antes del conocimiento científico históricamente hablando? Popper es claro en este punto: antes hubo conocimientos precientíficos (explicaciones míticoreligiosas acerca de la realidad). La ciencia nace como una crítica a esos conocimientos precientíficos. Una crítica que ofrece una propuesta de interpretación que deberá ser a su vez criticada (refutada). ¿Cuándo ocurrió eso? En la Grecia antigua, con Tales de Mileto quien dijo a alguno de sus discípulos: "así es como veo yo las cosas; como creo yo que son las cosas. Trata de mejorar mis enseñanzas" ${ }^{\prime 37}$.

De modo que quienes dieron los primeros pasos en el mundo de la ciencia - los griegos en el siglo VI y V antes de Cristo- no lo hicieron a partir de la nada. Lo hicieron a partir de unos conocimientos previos que les plantearon un conjunto de problemas: movimiento, estructura del cosmos, nacimiento y muerte de las sociedades. Esos conocimientos previos estaban plasmados en relatos orales y escritos que, en sus fuentes originales (dioses), era patrimonio de los elegidos, intérpretes de la verdad original. Lo que esas verdades decían era incuestionable. Cualquier cambio era visto no como eso sino como una recuperación o vuelta a lo original. Se trataba de ortodoxias. En palabras de Popper:

"Trataré de plantear el problema de manera tajante. En todas o casi todas las civilizaciones, nos topamos con algún tipo de enseñanza religiosa o cosmológica, y en muchas sociedades nos encontramos con escuelas. Ahora bien, las escuelas, en especial las escuelas primitivas, poseen todas ellas, según parece, una estructura y una función características. Lejos de ser lugares de discusión crítica, se imponían como tarea impartir una doctrina definida y preservarla pura e intacta. La misión de la escuela es transmitir a la generación siguiente la tradición, la doctrina de su fundador, su primer maestro, y a tal 
clecto, lo más importante es mantener la doctrina inviolada. Una escuela de este tipo jamás admite una idea nueva. Las ideas nuevas son herejías y llevan a cismas, pues si un miembro de la escuela intentase cambiar la doctrina, sería expulsado por hereje. Más, por regla general, el hereje pretende que la suya es la verdadera doctrina del fundador... De esta manera, todos los cambios de doctrina, si es que los hay, resultan cambios subrepticios. Todos se presentan como repeticiones de las verdaderas aseveraciones del maestro...

" [Exceptuando a los pitagóricos] podríamos decir que el carácter de la filosofía griega y de las escuelas filosóficas es asombrosamente diferente del lipo de escuela dogmática aquí descrita... Las ideas nuevas se proponen como tales y surgen como resultado de la crítica abierta... Es una tradición lo que permite o alienta las discusiones críticas entre diferentes escuelas, dentro de una y la misma escuela"’3x.

La cicncia surge cuando lo que dicen los primeros científicos no es una verdad incuestionable, sino más bien todo lo contrario. Ello supone la "publicidad" del saber, que no puede ser patrimonio de sectas o individuos elegidos. Y esa publicidad es posibilitada por el lenguaje, concretamente el lenguaje escrito. Es el lenguajc escrito el que mejor permitió discutir sobre las ideas que se iban proponicndo, pero de un modo revolucionario: avanzando sobre lo que ya se había dicho. Desde los griegos y luego con la invención del libro en serie la publici(lad del saber ha ido en aumento creciente. Y este proceso llega hasta nuestros lías. "Por vez primera en la historia de la evolución de la vida en nuestro maravilloso planeta - escribe Popper - la invención del lenguaje hizo posible la cxistencia de contenidos intelectuales objetivos; y al permitirnos considerar los contenidos intelectuales como objetos, nos hizo posible la crítica y la crítica de nosotros mismos. El paso siguiente fue el descubrimiento de la escritura. Pero el paso más importante fue la invención del libro y de la competencia crílica entre libros" "3."

Ahora bien, ¿qué había antes del saber precientífico? Volviendo la vista hacia atrás, hay que remontarse hasta los orígenes del hombre, aquel primer homo sapiens (hace unos 100-50 mil años) que por sus "obras" y su estructura corporal (capacidad craneana, andar erecto, uso de las manos, rudimentos de lenguaje, frente erguida) identificamos como un ser humano. Este hombre (o los varios de tipos de hombre que existieron en ese entonces ${ }^{4(1)}$ ), ¿solo hacía cosas, las tocaba, las ciambiaba, sin ningún tipo de conocimiento? ¿Primero hizo cosas, las tocó, palpó, etc., y luego las conoció? Entonces, ¿por qué identificarlo como homo sapiens?

Es razonable suponer que algún tipo de conocimiento (de conjetura mental accrca de lo que eran las cosas fuera de la mente) existía ya en él. Es decir, se puede suponer que tocar, palpar y transformar estaban orientados por un conocimiento muy rudimentario, pero que es el que permite asumir que las vasijas, las piedras talladas, las cavernas y sus "dibujos" son una creación humana. Ya sea 
que se le llame trabajo o praxis, en ambos casos debe haber algún conocimiento involucrado ${ }^{41}$.

Quizás hasta aquí sea relativamente fácil ponerse de acuerdo: cuando hablamos del hombre, ya desde sus orígenes, no podemos desligar la práctica (experiencia) del conocimiento y este último del lenguaje. Popper lanza la conjetura de que ese conocimiento fue, ya en aquel momento, algo previo a la experiencia, a la actividad práctica de los primeros hombres. ¿Cómo es eso?

Pues bien, -y aquí viene la parte polémica de la propuesta popperiana- el conocimiento de los primeros hombres estuvo precedido por el conocimiento de sus antecesores en la escala evolutiva: los hominidos y el australopithecus (4 millones de años) hasta el homo sapiens arcaicus (500 mil años). Estos grupos cuasi humanos tuvieron una especie de preconocimiento humano, es decir, un "posicionamiento cognoscitivo" en el que sólo aparecían precisamente rastros muy primitivos de lenguaje. En otras palabras, en este momento no se había inventado el lenguaje, lo cual creaba una barrera para la constitución de un conocimiento propiamente humano ${ }^{42}$; lo que había, por tanto, era un "conocimiento" prelingüístico.

¿Y antes de esto qué había? Estaba -y está- el "conocimiento" animal, que desciende en la escala zoológica desde los mamíferos superiores hasta los orígenes mismos de la vida, es decir, hasta los primeros seres vivos. Este "saber" muy básico tiene que ver con las "anticipaciones" de los vivientes a la situación futura del medio ambiente. Es decir, se trata de un saber adaptativo que es vital para la sobrevivencia de las especies.

"La vida tiene que anticipar desde el principio en algún sentido el futuro del medio ambiente, esto es, todas esas circunstancias futuras del medio ambiente... La vida tiene que estar adaptada a las condiciones futuras del medio ambiente; $y$ en ese senticlo, aqui el saber general es anterior al saber momentáneo, el saber particular. Desde el principio la vida tiene que haber sido dotada de un saber general, el saber que usualmente denominamos saber de las leyes naturales. Por supuesto no un saber en el sentido de saber consciente. La consciencia es una cosa totalmente distinta. Así es, pues, como llego a atribuir a los seres primitivos un saber..."4?.

Para Popper, ya en las amebas se pueden rastrear con claridad los primeros esquemas cognoscitivos en la escala zoológica bajo la forma de ensayo y error. ¿A partir de qué se ensaya? A partir de "expectativas" genéticamente determinadas. "El perro espera a su amo a las cinco y media. Se pone intranquilo, se ve que se preparara a que el amo llegue a casa a las cinco y media. Esto son formas de saber, y esas formas de saber son siempre expectativas. De manera semejante la flor espera que por la tarde refresque la temperatura: se prepara para ello"\$4. Las expeclativas están genéticamente determinadas, es decir, están posibilitadas por la estructura genética de los vivientes. Por ellas, los seres vivos "son activos, en cuanto que tantean continuamente, tantean en todas las direcciones, como los escarabajos" 4 . 
Dicho de otro modo, los seres vivos están dotados de una determinada capacidad de expectativas. Esas expectativas acerca de cómo será el entorno (si variará o se mantendrá) los llevan a ensayar respuestas que si son acertadas le permitirán sobrevivir (además, se harán parte de su saber biológico); si no, tcrminarán con su vida, es decir, serán un ensayo ertado. Para Popper, este mecanismo de ensayo y error se reproduce a lo largo de la evolución; es el que permite que individuos y especies se extingan o sobrevivan. Todo depende de si los cnsayos son exitosos o si, por el contrario, conducen al error. Los animales con capacidad de ensayos exitosos tienen mayores perspectivas en la lucha por la existencia. Son los que dejan descendencia. Los seres vivos "buscan y encuentran; están a la búsqueda de un entorno mejor, de un mundo mejor... Y son activos en esa búsqueda de un mundo mejor. En esa búsqueda ya tienen que adaptarse de alguna manera, como he dicho; entonces ya han de tener un cierto saber general. Y entonces llegan por añadidura las mutaciones y nuevas adaptaciones. Y esto es la empiria: ensayo y error. La empiria es la que dice 'no'. Todos los ensayos que no obtienen éxito —csto cs, los errores - se eliminan. Y esa climinación conduce entonces de alguna manera a nuevos ensayos. En esto juegan un papel fundamental las mutaciones y otros medios, los cuales modifican el ADN (para modificar la herencia)" "t6.

Por tanto, el error en el mundo biológico es un asunto de vida o muerte. Así es, salvo para el hombre. Para este último, sigue operando el esquema de ensayo y error (el mismo esquema de la ameba y del resto de animales) solo que con una novedad: la invención del lenguaje. El hombre formula sus expectativas (su conocimiento) en un lenguaje (teorías, religiones, filosofías) que puede independizarse de él, de su cuerpo. Por esa razón, los' ensayos que el hombre hace no involucran un comportamiento inmediato $y$, aunque sean errados, le permiten sortear el riesgo de morir. En el hombre, por la invención del lenguaje, el ensayo y el error se trasladan al mundo de las ideas y del debate público. Se ensayan ideas sobre cómo es la realidad, que si son erradas son desechadas (mueren), pero no necesariamente deben morir sus portadores. Por su parte, las ideas exitosas no indican (ni suponen) superiodidad biológica alguna, sino sólo mayor aceptación social de esas ideas. Para Popper, la ciencia es una especialización de esta posibilidad. De lo que se trata en la ciencia es de matar sistemáticamente los conocimientos vigentes, para reemplazarlos por otros.

Se asume el esquema de ensayo y el error, pero para buscar conscientemente el error en los ensayos propuestos (conjeturas) o en los ensayos que se han dado por exitosos (teorías establecidas). Falsar las teorías (conjeturas) es buscar expresamente sus errores. La ciencia, pues, es el último peldaño en la cadena evolutiva. Con ella, las teorías mueren para que vivan los hombres. Aquí los errores significan nuevos avances en el conocimiento, el cual pasa por la muerte de las ideas equivocadas (las que no resisten la prueba de la falsación). 
En resumen, la epistemología genética de Popper parte de una visión evolutiva del conocimiento que arranca de las "expectativas" de los animales inferiores, pasa por el "preconocimiento" de los homínidos hasta desembocar en el humano, cuya clave es el lenguaje. En la historia del hombre también se produce un desarrollo del conocimiento, desde las concepciones precietíficas - mítico-religiosas - hasta el surgimiento de la ciencia. El conocimiento humano es la culminación de un proceso adaptativo que consta los tres niveles siguientes: adaptación genética, conducta adaptativa y descubrimiento científico.

"La adaptación, en los tres niveles, empieza a partir de una estructura heredada que es básica. En el nivel genético es la estructura de genes del organismo. A esta estructura corresponde, en el nivel conductual, el repertorio innato de los tipos de conducta de que dispone el organismo; y en el nivel científico, las conjeturas o teorias científicas dominantes. Estas estructuras se transmiten siempre por instrucción en los tres niveles: por replicación de la instrucción genética codificada, en los niveles genético y conductual; y mediante la tradición social e imitación, en los niveles conductual y científico. En los tres niveles, la instrucción procede desde dentro de la estructura. Si ocurren mutaciones, variaciones o errores, entonces estas son nuevas instrucciones, que también surgen desde el interior de la estructura, y no desde fuera, no desde el medio biológico" 47 .

En la actualidad, con un conocimiento científico ya consolidado, la ciencia comparte el espacio cognoscitivo con otras producciones mentales (el conocimiento ordinario, la religión, la filosofía, el arte y la pseudo ciencia) con los cuales dialoga a la vez que trata de demarcarse. Ese espacio cognoscitivo -el espacio de las producciones mentales objetivadas - es llamado por Popper el "mundo 3"., rclacionado con los también llamados por este autor "mundo 1" y "mundo 2".

\subsection{Teoría de los mundos 1,2 y 3}

En este apartado se toca lo que se puede llamar "cosmovisión" popperiana. El mundo 3, precisamente, está formado por esos productos del espíritu entre los cuales cobran gran relevancia las producciones ideas científicas. Ese mundo 3 cstá formado por ideas, sueños, teorías, esperanzas, etc., que ya no pertenecen a sus creadores, pues existen fuera de ellos, como patrimonio social. "En el sentido amplio de la palabra — dice Popper-, denomino 'mundo 3' al mundo de los productos del espíritu humano; en el sentido restringido, particularmente al mundo de las teorías, comprendidas las falsas teorías; y al mundo de los problemas científicos, inclusive las preguntas por la verdad y la falsedad de las distintas ıcorías. En sentido amplio, también pertenecen al mundo 3 las poesías y las obras de arte, como por ejemplo las óperas y conciertos de Mozart. Pero si se quicrc, puede denominarse al mundo de las obras de arte como mundo 4. Es una cucstión terminológica" ${ }^{\text {4x. }}$. 
Ahora bien, lo propio del mundo 3 es estar formado por las producciones espirituales humanas objetivadas, para lo cual es de suma importancia el lenguaje. "Lo nuevo del lenguaje humano es que puede describir y argumentar... Yo me represento la cuestión de manera que la invención del lenguaje específicamente humano está en conexión con la posibilidad de relatar, de narrar lo que acontece... Simultáneamente surge la posibilidad de contar cuentos. Esos cuentos o historias o mitos son también su origen explicaciones teóricas: los comienzos de la ciencia en los griegos se remontan a Homero y Hesíodo; los comienzos del arte, las pinturas rupestres prehistóricas de cacerías de animales, son historias mágicas; los artes egipcio y asirio son en gran parte ilustraciones de historias o ilustraciones de su historia contemporánea. Así se llega al desarrollo de un mundo 3”49.

Luego, está el mundo 2, el mundo de la subjetividad y decisiones humanas. En este mundo surgen las producciones que integrarán el mundo 3. Asimismo, el mundo 3 influye decisivamente en el mundo 2, es decir, en las decisiones y subjetividad humanas. "Utilizaré el término 'mundo 2' para referirme al mundo de nuestra experiencia... Presumiblemente también los animales tienen experiencias... Es perfectamente posible que todos los seres vivos, incluidas las amebas, tengan experiencias. Según sabemos por los sueños o por los pacientes con fiebre alta o condiciones similares, existen experiencias subjetivas en un grado de consciencia muy diferente. En los estados de profunda inconsciencia e incluso cuando dormimos sin soñar perdemos totalmente la consciencia, y con ella nuestras experiencias. Pero podemos suponer que existen también estados inconscientes, y que estos pueden incluirse en el mundo $2^{\prime \prime 50}$.

Finalmente, el mundo I: el mundo de los procesos físicos (materiales): masas, velocidades, átomos, compuestos químicos, electricidad, leyes biológicas, movimiento de los astros, etc. "Partes de la realidad en la que vivimos son materiales. Vivimos en sobre la superficie de la tierra que la humanidad ha conquistado sólo en fecha muy reciente... Sabemos muy poco sobre su interior, y es preciso subrayar es 'poco'. Aparte de la tierra, existen el sol, la luna y las estrellas. El sol, la luna y las estrellas son cuerpos materiales. La tierra junto al sol, la luna y las estrella, nos da nuestra primera idea de un universo, de un cosmos... Hemos descubierto dos tipos de cuerpos sobre la tierra: animados e inanimados. Ambos pertenecen al mundo material, al mundo de los objetos físicos. A este mundo lo clconimaré "mundo l'"s!.

\section{Consideraciones}

El mundo I fue el primero, desde un punto de vista evolutivo. Posteriormentc, surgieron los mundos 2 y 3 . El mundo 2 abarca tanto a los animales (con la más elemental subjetividad) como al hombre con sus complejos procesos subjetivos. El mundo 3 es específicamente humano. Este mundo 3 influye sobre el mundo 2 tanto de hombres como de animales. Pero también influye sobre el mundo 1: estructura de la tierra, cambios en materiales, energía nuclear, deshe-

Epistemología y racionalismo critico (Los griegos y Korl Popper) 
chos... Por su lado, el mundo 3 se sostiene en procesos del mundo 2 y 3 . Por ejemplo, la discusión crítica de teorías involucra procesos subjetivos y acciones humanas. Asimismo, esa discusión involucra movimientos físicos, energía, etc., o cuando es escrita la utilización de materiales y productos químicos (papel, (inta, luz).

"Resalto la existencia de tres mundos, en parte autónomos, pero que presentan interacción: el mundo físico 1, el mundo de los procesos de consciencia 2 y el mundo 3, el mundo de los productos del espíritu humano... He intentado mostrar que el mundo físico 1 está abierto ante el mundo psíquico 2 ... He intentado mostrar, particularmente, que el mundo 2 se encuentra en estrecha unión o interacción con el mundo 3, que la autonciencia humana, o la consciencia del yo, es incomprensible sin la existencia del mundo 3. Que la consciencia del yo está anclada en el mundo 3. Por lo tanto, genéticamente el mundo humano 2 es tanto un producto del mundo 3, como el mundo 3 es un producto del mundo 2. Dicho de otra manera: somos un producto de nuestros productos, esto es, de nuestra civilización, a la que todos nosotros contribuimos"

En definitiva, para Popper, lo más relevante del mundo 3 son las teorías científicas. La evolución humana ha desembocado en la creación de ese mundo. Porque existe un mundo 3 es que el hombre ha podido vencer las leyes biológicas que exigen la supervivencia del más apto. El cambio se ha dado a favor de la supervivencia de las ideas más aptas, sin que las ideas menos aptas supongan la muerte de quienes las sostienen. Con Popper, pues, entramos de lleno en el terreno de la epistemología moderna. Sus aportes son claves para posicionarnos ante los problemas epistemológicos más relevantes.

\section{Conclusiones}

Recapitulando, las lecciones generales de la postura popperiana son las siguientes:

1. Importancia de la teoría: no hay avance en la ciencia sin un dominio del campo teórico en el que se mueve quien hace ciencia. Esto constituye un "a priori" del científico. Lo propio de la ciencia es añadir conocimiento: de lo que no se sabe a lo que ya se sabe.

2. La experiencia no es un punto de partida, sino de llegada para cl conocimiento científico;

3. El dogmatismo es lo más opuesto al quehacer científico, pues lo más propio de este es falsar sus propios resultados, no sostenerlos de un modo necio.

4. La discusión crítica es central en el desarrollo científico ${ }^{53}$. Mediante esta discusión se examinan permanentemente las teorías establecidas; se eliminan las que ticnen errores y se reemplazan por otras (o se modifican las establecidas). 
5. Es importante "demarcar" lo que es ciencia de lo que no lo es, aunque así lo crea el público o quienes se dedican al quehacer pseudocientífico.

6. El esquema: problema-conjetura-refutación-problema opera en el mundo científico se den cuenta o no de ello los científicos. Es el que permite avances en la ciencia.

7. Ahí donde no opera tal esquema no se tiene discusión o debate científico, crean lo que crean quienes participan en el debate o el público.

8. Para Popper, el debate científico no se mide por el éxito de tal o cual idea o conjunto de ideas, ni por los muchos seguidores que la misma tiene (las religiones suelen llevar la delantera en esto).

9. Por lo general, los planteamientos no falsables son los que tienen más éxito público y los que generan más seguidores (quizás porque tienen una estructura similar a la de la religión).

10. El conocimiento científico establecido (es decir, actual) está inserto en un marco de conocimientos más amplios: conocimiento ordinario (común), fillosolía (metafísica), religión y pseudociencias. Es de ellos que se "demarca", pero también toma problemas, es decir, le sirven como horizonte problemático amplio. Y también integra muchos de sus logros en ellos.

11. Las ciencias naturales no son un modelo para las ciencias sociales.

12. Tanto las ciencias naturales como las sociales tienen un soporte teórico que es fundamental y que es el que orienta el quehacer de los científicos, sean cstos o no conscientes de ello.

13. Que para hacer ciencia natural o social se tienen que dominar los campos tcóricos respectivos. De hecho, los que hacen ciencia natural o social (y aportan a ellas) dominan esos campos teóricos en tanto que fueron educados en ellos.

14. Que el proceder metodológico no es lo que distingue a las ciencias naturales y sociales, sino el campo de problemas que las ocupan: realidades no humanas y realidades humanas.

\section{Notas}

1. Cìr. González, L.A. "Notas en torno al debate explicación-comprensión”. Realidad, No. 60, 1997. pp. 621-650

2. J. M. Mardones y N. Ursúa, Filosofía de las ciencias humanas y sociales. Materiales para una fundamentación cientifica. México. Fontamara, 1993, p. 34

3. K. Popper. El mundo de Parménides. Buenos Aires. Paidós, 1999, p. 16

4. La palabra "epistemología" ganó legitimidad en el debate académico en el siglo XX. gracias en gran medida al trabajo de Jean Piaget en el Centro Internacional de Epistemologia Genética. con sede en Ginebra, Suiza. Aquí conviene recordar que, para Kant. la tcoría del conocimiento se ocupaba de las condiciones, los límites y las posibi-

Epistemologia y racionalismo crítico (Los griegos y Korl Popper) 
lidades del conocimiento científico. Después de Kant, se ha terminado casi por reemplazar — prácticamente en el siglo XX- la expresión "teoría del conocimiento" por "epistemología", dejando como campo de estudio para esta última lo que en Kant era competencia de aquélla

5. X. Zubiri, El hombre y la verdad. Madrid, Alianza, 1999, p.15-16

6. Ver el análisis pormenorizado que hace de esta problemática K. Popper en su libro El mundo de Parménides, pp. 100 y ss. También Zubiri, en El hombre y la verdad, aborda resumidamente el tema de la verdad en Parménides, pp. 16 y ss.

7. Parménides, lragmento B 16, citado por K. Popper en Ob. Cit., p. 191

8. X. Zubiri, Cinco lecciones de filosofía. Madrid, Editorial Moneda y Crédito, 1970, p. 23

9. R. Mondolfo, Sócrates. Buenos Aires, EUDEBA, 1976, p. 63

10. K. Popper. Conjeturas y refutaciones. El desarrollo del conocimiento científico. Barcelona, Paidós, 1994, p. 32

11. Ibíd.

12. Textos tomados de Karl Popper: El mundo de Parménides. Buenos Aires, Paidós, 1999

13. R. Rorty, El giro linguiístico. Barcelona, Paidós, 1990, p. 50

14. "El problema central de la epistemología --dice Popper- ha sido siempre, y sigue siéndolo, el del aumento del conocimiento. $\gamma$ el mejor modo de estudiar el aumento del conocimiento es estudiar el del conocimiento científico". K. Popper, La lógica de la investigación cientifica. Madrid, Tecnos, 1999, p. 16

15. Este es el esquema de Francis Bacon, por ejemplo. Ver Novuun organum scientiarum. México, Porrúa, 1975

16. En la línea de los planteamientos de Henri Bergson, Gaston Bachelard tiene un estudio, La intuición del instante (Buenos Aires, Siglo Veinte, 1973) que se decanta en esta dirección.

17. K. Popper, La responsabilidad de vivir. Escritos sobre política, historia y conocimiento. Barcelona, Paidós, 1995, p. 30

18. Ibíd., pp. 30-31

19. K. Popper, El mito del marco común. En defensa de la ciencia y la racionalidad. Barcelona, Paidós, 1997, p. 95

20. K. Popper, La responsabilidad de vivir..., pp. 36-39

21. Es este punto es necesario referirse al necesario complemento de las tesis popperianas a partir del aporte de Thomas Kuhn, con sus reflexiones sobre los "paradigmas" y las "revoluciones científicas". Kuhn parte de la ciencia moderna. Hace una revisión de su historia y se encuentra con una serie de aspectos del quehacer científico que son cruciales para entender su modo de proceder. Este autor introduce la noción de "paradigma" como concepto fundamental para entender lo que los científicos hacen. Un paradigma está formado por las teorías, conceptos, palabras e ideas que sirven para explicar y entender determinados ámbitos de la realidad. Sean o no concientes de ello, es a la luz del mismo que los científicos buscan e interpretan los problemas que la realidad les va planteando. Un paradigma es como la "visión de mundo" que tienen los hombres de ciencia; ella les permite "ver" determinados problemas, realizar determinadas búsquedas y dialogar con sus colegas a partir de un marco conceptual común. Un paradigma es una visión de mundo compartida por una comunidad científica. Concretamente, Kuhn se refiere a los paradigmas establecidos, es decir, a los paradigmas fundados en 
las teorías predominantes. Desde su punto de vista, hacer ciencia es, ante todo, asimilar el paradigma establecido, sus conceptos, tesis y problemas. Una vez que los nuevos científicos han asimilado el paradigma predominante, están en condiciones de hacer ciencia sin mayores dificultades. Se han integrado a la ciencia "normal" y pueden desempeñarse en ella. Entonces, en el paradigma se juegan tres cosas: a) una integración institucional de los nuevos científicos; b) la posibilidad de hacer ciencia tal como está establecido; c) una visión preestablecida de la realidad y sus problemas, que es la que deberán aprender los nuevos científicos. Ahora bien, la ciencia normal no lo es todo, puesto que de cuando en cuando surgen desafíos a los paradigmas establecidos, ya que no todos los hombres de ciencia se integran plenamente a sus supuestos interpretativos. Desde los márgenes institucionales, nuevas ideas, tesis y concepciones van naciendo con la pretensión de explicar problemas que el paradigma vigente no puede explicar. Cuando esto sucede, algo importante puede suceder: las nuevas formulaciones teóricas pueden — si tienen suerte- no sólo explicar los problemas irresueltos por el paradigma vigente, sino también explicar lo que este explica, integrándolo como parte de una visión más global. Un intenso forcejeo se genera entre ambos grupos; cuando los abanderados comienzan a imponer su visión en la comunidad científica, que comienza a recelar del paradigma establecido se está a las puertas de una "revolución científica", es decir, de un cambio de paradigma, con el cual se iniciará de nuevo la dinámica de la ciencia normal. Con este nuevo paradigma, dice Kuhn, "los científicos adoptan nuevos instrumentos y buscan en lugares nuevos. Lo que es todavía más importante, durante las revoluciones científicas los científicos ven cosas nuevas y diferentes al mirar con instrumentos familiares en lugares en los que ya habían buscado antes". En definitiva, lo que Kuhn nos viene a decir es que no podemos hacer ciencia — sea natural o social- si no asimilamos los paradigmas científicos predominantes. Es decir, si no nos empapamos de las teorías, conceptos, valores y problemas propios de todo paradigma. Ellos nos permiten "ver" la realidad, ellos son la concepción del mundo que sirve de punto de partida para el trabajo científico. Si lo dijéramos con Popper, la ciencia establecida (los paradigmas establecidos) se están falsando permanentemente y, en virtud ello, mejoran y se afinan. Se trata de una falsación intrateorías establecidas. Pero pueden proponer conjeturas extra teorías establecidas, con el fin de reemplazarlas por otras. Si estas conjeturas extra teorías vigentes resisten, comienzan a reemplazar a las vigentes. Para Popper este cambio es lo más normal en el mundo de la ciencia, no tan excepcional como cree Kuhn. Cfr. Th. Kuhn, La estructura de las revoluciones científicas. México, FCE, 1985

22. K. Popper, Conjeturas y refutaciones. El desarrollo del conocimiento científico. Barcelona, Paidós, 1994, p. 13

23. D. Miller (Comp.), Popper. Escritos selectos. México, FCE, 1995, pp. 192-193

24. Ibíd., p. 193

25. K. Popper, El mito del marco común..., p. 154

26. D. Miller (Comp.), Popper. Escritos selectos..., p. 178

27. K. Popper, La responsabilidad de vivir..., p. 17

28. K. Popper, El mito del marco común..., p., 158

29. Para lo que sigue a continuación, cfr. Ibíd., pp. 160 y ss.

30. K. Popper, En busca de un mundo mejor. Barcelona, Paidós, 1996, p. 109

31. K. Popper, El mito del marco común..., p. 164

32. Ibíd., p. 168

Epistemología y racionalismo critico (Los griegos y Kon Popper) 
33. Ibíd.,

34. Ibid., p.169

35. K. Popper, En busca de un mundo mejor..., pp. 110-111

36. Las tesis de Popper son sumamente coherentes con las tesis defendidas por Jean Piaget, desde el Centro Internacional de Epistemología Genética, con sede en Ginebra. A diferencia de Popper, que aborda el problema del conocimiento desde la filogénesis. Piaget se centra en la ontogénesis. En esencia, uno de los problemas centrales de Piaget es cómo se desarrolla el conocimiento en la ontogénesis, es decir, en la evolución del individuo desde la primera infancia hasta la madurez. Su interés es explicar cómo emergen y se desarrollan las estructuras cognoscitivas, de las más elementales de ordenamiento espacio-temporal hasta las más abstractas de carácter lógico-matemático. Pues bien, estas estructuras cognoscitivas están ancladas en las estructuras genéticas del individuo y se desarrollan según etapas y fases cuya secuencia está fijada también genéticamente. Es decir, el conocimiento es un problema biológico: está constituido por estructuras de adaptación que progresivamente se van haciendo más complejas. El mecanismo biológico es el de la equilibración por la vía de la "asimilación" de recursos del entorno y la "desasimilación" de materiales que no sirven al organismo. La asimilación es un proceso activo del organismo sobre su entorno, regulada por sus estructuras genéticas. El conocimiento es una etapa más - la más avanzada- en el proceso de "equilibración" biológica. Con él, los modos de equilibración son más directos y eficaces. De aquí que el conocimiento es un mecanismo de adaptación que consiste cn la asimilación de datos de la realidad exterior a las estructuras del sujeto. Conocemos para estar mejor adaptados biológicamente al entorno. ¿Y la sociedad? ¿Y el aprendizaje? Son un motivo, un detonante para la emergencia de las estructuras cognoscitivas. Pero no algo que las crea o de lo cual dependan en forma exclusiva y determinante. En otras palabras, el conocimiento, en sus diferentes niveles, es una función de determinadas estructuras biológicas, cuya maduración es crucial para la emergencia de aquel. No es resultado de las experiencias o del aprendizaje. Cfr. J. Piaget, Introducción a la epistemología genética. Buenos Aires, Paidós, 1977; J. Piaget, Biología y conocimiento. México, Siglo XXI, 1969

37. La formulación es de Popper, quien dice tener razones para aceptar que "fue Tales quien fundó la nueva tradición de libertad (basada en una nueva relación entre maestro y discípulo), creando así un nuevo tipo de escuela palmariamente distinta de la escuela pitagórica. Parece haber sido capaz de tolerar las críticas y, lo que es más, parece haber creado la tradición de que se debería tolerar la crítica". El mundo de Parménides..., p. 42

38. K. Popper: El mundo de Parménides..., pp. 40-4I

39. K. Popper, En busca de un mundo mejor..., p. 141

40. Sobre este tema, Cfr. X. Zubiri, Siete ensayos de antropología filosófica. Bogotá, Universidad de Santo Tomás, 1982

41. Cfr. A. L. Merani, De la praxis a la razón. Mano, cerebro y lenguaje. Definición de hombre. México, Grijalbo, 1975

42. La tesis de fondo en este punto es la que sostiene que el conocimiento humano es inseparable del lenguaje, lo cual no quiere decir que otros seres vivos no tengan algún lipo de conocimiento. Pero se trata de un conocimiento no lingüístico y, por ello, no humano. Giovani Sartori, un autor aparentemente alejado de estas preocupaciones epistemológicas, lo dice así: "las palabras sirven tanto para hablar como para pensar, 
y por más que el lenguaje no es pensamiento, no existe el uno sin el otro...Pensar es pensar en algo, de algo, propósito de algo. Es, por lo tanto, pensamiento discursivo, pensamiento que tiene por sustancia el lenguaje; no podemos pensar sin palabras...". G. Sartori, La política. Lógica y método de las ciencias sociales. México. FCE, 2000, pp. 30-32

43. K. Popper, La responsabilidad de vivir..., p. 114-115

44. lbíd., p. 116

45. lbíd., p. 119

46. Ibid., p. 120

47. D. Miller (Comp.), Popper. Escritos selectos..., p. 84

48. K. Popper, La responsabilidad de vivir..., p. 83

49. Ibid.. pp. 94-95

50. K. Popper, En busca de un mundo mejor..., p. 23

51. Ibid., p. 22

52. K. Popper, La responsabilidad de vivir..., p. 95

53. En este punto es importante tomar nota de la propuesta de Imre Lakatos en torno al desarrollo del conocimiento científico. En efecto, Lakatos toma posición ante la problemática planteada por Popper (y Kuhn): el problema de cómo avanza y se desarrolla la ciencia. Para él, el avance de la ciencia consiste en la formulación de grandes teorías (paradigmas, en la terminología de Kuhn): conceptualizaciones lo más completas posibles de determinados ámbitos de la realidad, que siempre serán incompletas. Es decir, el desarrollo científico es desarrollo en la teoría, de la cual surgen los problemas a investigar, las propuestas metodológicas y los nuevos problemas. En este sentido, Lakatos inscribe su postura en el marco de la problemática poskantiana. Él también arranca de la ciencia madura, pero esta en su opinión no está regida por el esquema de ensayo y error, como cree Popper. De aquí surgen dos críticas a Popper: (a) Para Lakatos, la tesis popperiana del ensayo y del error corre el peligro de entender el desarrollo de la ciencia como una suma de casos aislados que, en su conjunto, conforman el cuerpo completo de ámbito científico determinado; y (b) El planteamiento popperiano -dice Lakatos- puede dar pie a una concepción "ingenua" del procedimiento de las conjeluras: cualquiera podría, con un mínimo conocimiento, lanzar cualquier conjetura. Lakatos lo dice sin preámbulos: "La ciencia madura no es un procedimiento de ensayo y error que consista en hipótesis aisladas más sus confirmaciones y sus refutaciones". En su opinión, los grandes logros de la ciencia - las grandes teorías - no son hipótesis aisladas o descubrimientos de nuevos hechos, sino "programas de investigación". Es decir, esquemas normativos (institucionales) bien establecidos y definidos que plantean los problemas a investigar, las interpretaciones a aceptar y las experiencias (experimentos) a considerar como legítimas. Dentro de estos programas hay una parte nuclear (el núcleo del programa de investigación) que es la sustantiva tanto desde el punto de vista teórico como metodológico que los distingue de otros. Las experiencias, pues, no tienen la función de falsar las conjeturas (o teorías) sino para medir la fortaleza o degeneración de los programas de investigación. Una ciencia es madura cuando se concreta en programas de investigación bien definidos que ciertamente pueden ser rivales entre sí. Es decir, no hay un solo programa de investigación en una ciencia madura, sino varios. Y entre estos se establece una guerra de desgaste para determinar cuál es el que predominará. Ahora bien, el predominio de un programa de investigación no depende tanto (o sólo) de la fortaleza de su aparato teórico o de las falsaciones a las que ha sido

Epistemologia y racionalismo crítico (Los griegos y Karl Popper) 
sometido, sino del respaldo institucional con el que cuente. Los programas de investigación son ellos unas instituciones de aprendizaje social (socialización) para las nuevas generaciones científicas. En fin, según Lakatos, para hacer ciencia hay que insertarse en un programa de investigación determinado; de lo contrario se estará condenado a la marginación intelectual. Esto es así tanto en las ciencias naturales como en las ciencias sociales. En ambas, el avance es teórico (en las formulaciones teóricas), pero ese avance se realiza a través de programas de investigación que se disputan la supremacía. Cfr. I. Lakatos, La metodología de los programas de investigación. Madrid, Alianza, 1982 